\title{
Shape Control of Silica Powder Formation
}

\author{
Marwa Nabil1 ${ }^{*}$, Hussien A. Motaweh² \\ ${ }^{1}$ Advanced Technology and New Materials Research Institute, City for Scientific Research and Technology Applications, \\ Alexandria, Egypt \\ ${ }^{2}$ Department of Physics, Faculty of Science, Damanhour University, Damanhour, Egypt \\ Email: *marwamoh2000@yahoo.com
}

How to cite this paper: Nabil, M. and Motaweh, H.A. (2019) Shape Control of Silica Powder Formation. Journal of Materials Science and Chemical Engineering, 7, 49-55.

https://doi.org/10.4236/msce.2019.73004

Received: February 19, 2019

Accepted: March 25, 2019

Published: March 28, 2019

Copyright $\odot 2019$ by author(s) and Scientific Research Publishing Inc. This work is licensed under the Creative Commons Attribution International License (CC BY 4.0).

http://creativecommons.org/licenses/by/4.0/

\begin{abstract}
The purpose of the present research is the different morphologies production of crystalline and amorphous-silica powder. It's a basic material for many pharmaceutical and environmental applications as well. And, it's produced using the combination of the alkali chemical etching process and the ultra-sonication technique. The critical preparation conditions are $\mathrm{KOH}$ concentration (weight \%) and the sonication time (hour). The paper presents the chemical mechanism of the silica particle formation as well as the different morphology. The results show the formation of crystalline and amorphous-porous-silica particles in the micrometer range with the porous order network that has pore sizes range in micrometer too. This synthetic uses commercial silicon, which could be useful for large-scale production. Also, the nano-sphere and nano-cubic shapes of silica powder are formed starting by commercial silicon powder.
\end{abstract}

\section{Keywords}

Amorphous Materials, Porous Materials, Powder Formation, $\mathrm{SiO}_{2}$

\section{Introduction}

The silica $\left(\mathrm{SiO}_{2}\right)$ powder is noted as competent materials because of their unique characteristics (low density, high surface area and high specific strength) [1] [2] [3]. $\mathrm{SiO}_{2}$ is a very interesting material for using in many fields [4] [5]. And, it's proving a promising material due to its good thermal and mechanical stability. In addition, it has many excellent physical and chemical properties [6] [7].

There're various porous- $\mathrm{SiO}_{2}$ preparation techniques in previous studies [8]; the synthesis of porous- $\mathrm{SiO}_{2}$ thin films is described with respect to pore structures [9]. It's derived from the presence of active (OH-groups) on the particle surface. So, the ( $\mathrm{Si}-\mathrm{O}-\mathrm{Si}$ ) linkages between neighboring particles are produced as 
a result of the hydrogen-bond formation. In case of the (OH-groups) deactivation, the nanoparticles aggregation is stopped [7]. There are several chemical techniques used for controlling the particle shapes, and size of fine $\mathrm{SiO}_{2}$ particles [1] [8]. In this work, it demonstrated a combination between wet alkali chemical etching (ACE) process and ultra-sonication technique that controls the $\mathrm{SiO}_{2}$ shapes.

\section{Materials \& Methods}

The combination of ACE process and ultra-sonication technique is attractive because of its simplicity. The preparation of porous- $\mathrm{SiO}_{2}$ different morphologies is started by $7 \mathrm{~g}$ commercial polycrystalline Si-powder (99\%, Sigma-Aldrich). It's added to the NPA (30 Vol \%), $\mathrm{KOH}_{\text {conc }}(3,4.5$, and 6 weight \%) and at different time values $(2,3,4$, and 5 hours). The product is filtered, washed, and then slowly dried at room temperature. The structure of the nano-porous- $\mathrm{SiO}_{2}$ is characterized using X-ray diffraction (XRD; $\mathrm{Cu} \mathrm{K} \alpha$ radiation of $1.5405 \AA$, Shimadzu 7000 diffractometer). The scanning electron microscope (SEM; JEOL-JSM-5300) and transmission electron microscope (TEM; JEOL, Japan), present the nano-porous- $\mathrm{SiO}_{2}$ morphology. In addition, the formation of nano-porous- $\mathrm{SiO}_{2}$ chemical bonds is determined by Fourier Transform Infrared spectroscopy (Shimadzu FTIR-8400s, Japan).

\section{Results \& Discussion}

$\mathrm{XRD}$ is considered as a reference technique for the product powder characterization [10]. Figure 1 shows the diffraction features of the polycrystalline-Si, $\left(\mathrm{SiO}_{2} / \mathrm{Si}\right)$, crystalline- $\mathrm{SiO}_{2}$ and amorphous- $\mathrm{SiO}_{2}$ using a combination between $\mathrm{ACE}$ and ultra-sonication process [at different values of $\mathrm{KOH}_{\text {conc }}$ and $(t)$ ]. Figures $1(\mathrm{a})$-(c) show the diffraction patterns at $28.22^{\circ}, 47.19^{\circ}, 56.03^{\circ}, 68.97^{\circ}$, $76.25^{\circ}, 87.93^{\circ}$, and $94.8370^{\circ}$ (JCPDS card nos. 01-079-0613 and 00-027-1402) [11], which correspond to planes (111), (220), (211), (400), (331), (422), and (511), respectively. As shown in Figure 1(b) ( $t=3$ hours), amorphous- $\mathrm{SiO}_{2}$ appears as a broadened peak at $2 \theta=21.5^{\circ}$ for producing $\left(\mathrm{SiO}_{2} / \mathrm{Si}\right)$. And, Figure 1(b) and Figure 1(c) ( $t=4$ hours) show the enhancement broadening peak that corresponds to the crystalline- $\mathrm{SiO}_{2}[12]$.

Finally, Figure 1(b) and Figure 1 (c) ( $t=5$ hours), the $\mathrm{SiO}_{2}$-peak high intensity appeared at $2 \theta=20^{\circ}$ that corresponds to the complete transformation to amorphous- $\mathrm{SiO}_{2}$ [13]. Then, the preparation conditions during the crystalline- $\mathrm{SiO}_{2}$ formation are [ 4.5 and 6 weight $\% \mathrm{KOH}$ at $t=4$ hours]. But, the amorphous $-\mathrm{SiO}_{2}$ is formed at $t=5$ hours. From the reported data, $(t)$ has a great effect in the controlling process during the $\mathrm{SiO}_{2}$ type preparation.

Figure 2 shows the chemical bonding formation of $\mathrm{SiO}_{2}$ types; the broadening bands (820 and $1300 \mathrm{~cm}^{-1}$ ) assign to $\mathrm{Si}-\mathrm{O}-\mathrm{Si}$ asymmetric-stretching-vibrations [14], and the narrow bands (1089 and $1093 \mathrm{~cm}^{-1}$ ) correspond to the $\mathrm{SiO}_{2}$ presence [15]. The bands ( 801 and $803 \mathrm{~cm}^{-1}$ ) are due to symmetric-stretching-vibrations of siloxane-groups ( $\mathrm{Si}-\mathrm{O}-\mathrm{Si}$ ), as shown in Figure 2(a) and Figure 2(b), respectively. 

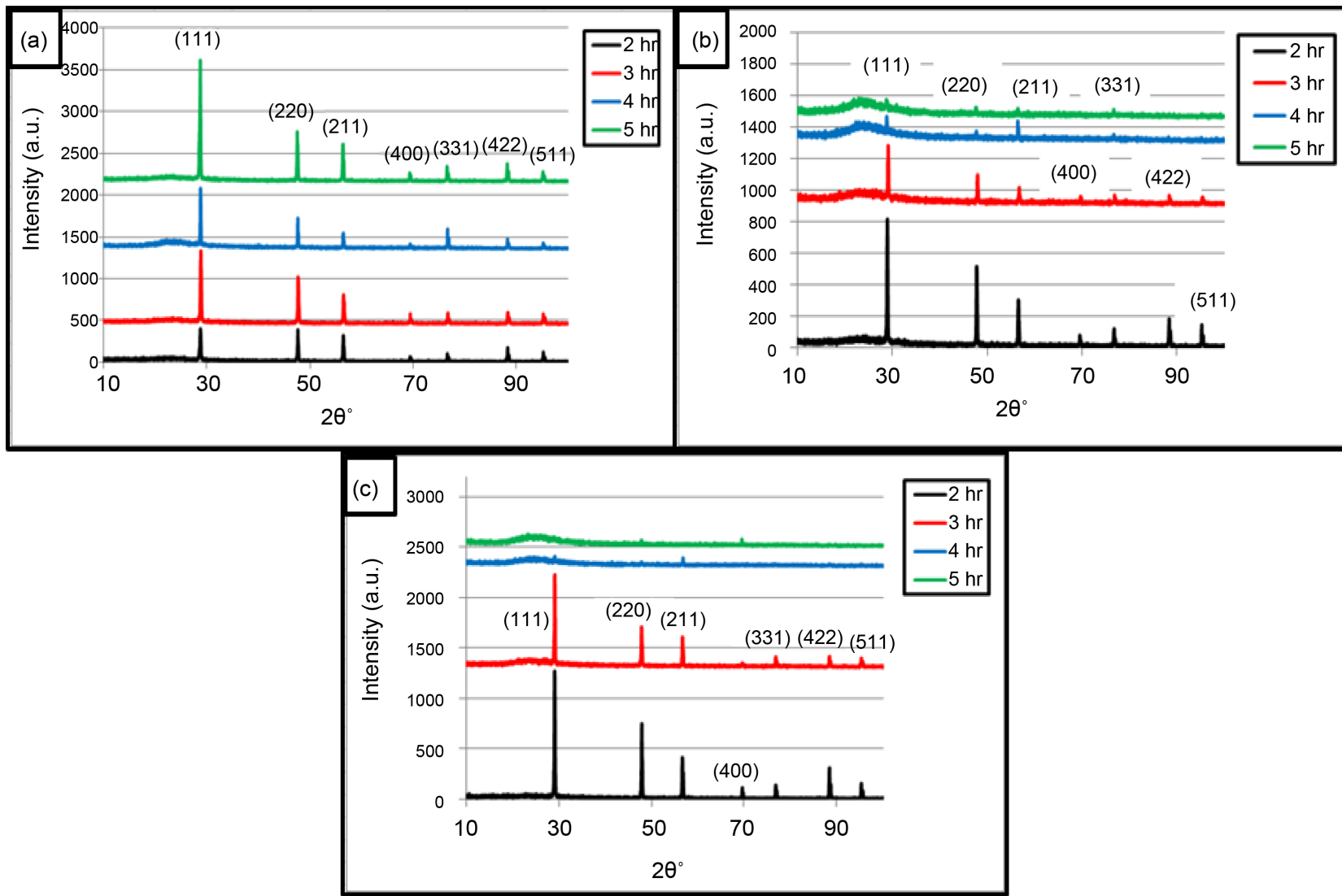

Figure 1. XRD of Si-polycrystalline, $\mathrm{SiO}_{2} / \mathrm{Si}$ crystalline $\mathrm{SiO}_{2}$ and amorphous- $\mathrm{SiO}_{2}$ powders obtained with different $\mathrm{KOH}_{\text {conc }}$ and $t$; (a) $3 \mathrm{wt} \% \mathrm{KOH}$, (b) $4.5 \mathrm{wt} \% \mathrm{KOH}$, and (c) $6 \mathrm{wt} \% \mathrm{KOH}$.
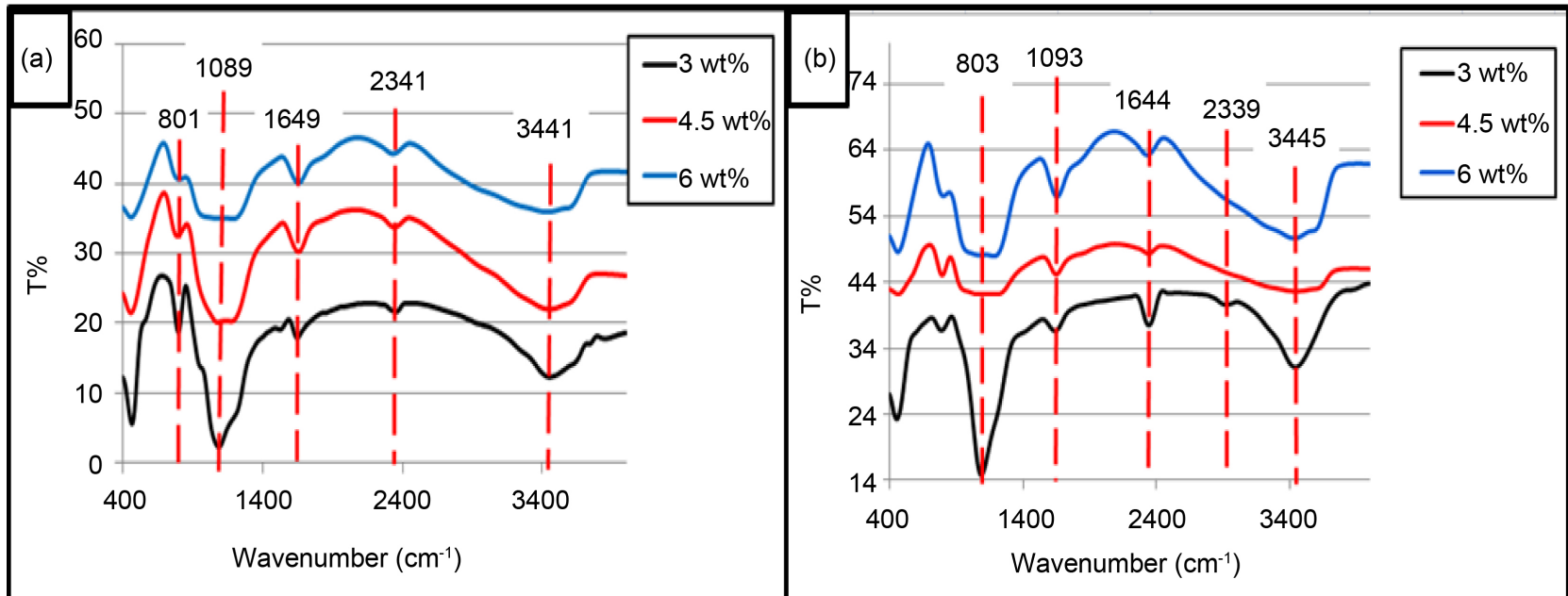

Figure 2. FTIR of the precipitated $\mathrm{SiO}_{2}$-nanoparticle obtained with different $K O H_{\text {conc }}$ prepared by ACE; (a) $t=4 \mathrm{hr}$, (b) $t=5 \mathrm{hr}$.

The $\mathrm{O}-\mathrm{H}$ bending-vibration bands of the adsorbed water are located at 1649 and $1644 \mathrm{~cm}^{-1}$, and the $\mathrm{O}$-Hstretching-vibration bands at 3441 and $3445 \mathrm{~cm}^{-1}$ (at $t=$ 4 and 5 hours). The presence of water molecules proves that the amorphous- $\mathrm{SiO}_{2}$ chemical formula is close to $\mathrm{SiO}_{\mathrm{x}} \mathrm{yH}_{2} \mathrm{O}$ form [16]. In addition, the shoulder at $2341 \mathrm{~cm}^{-1}$ is assigned to the stretching-vibrations of $\mathrm{Si}-\mathrm{OH}$ groups in 
the amorphous- $\mathrm{SiO}_{2}$ structure [15], which also confirm the XRD data as shown in Figure 1.

Figure 3 presents SEM-micrographs of $\mathrm{SiO}_{2}$ powder morphology; Figure 3(e) shows the inversely proportional relation between $(t)$ and $\mathrm{SiO}_{2}$ construction. At 6 weight $\% \mathrm{KOH}$; Figures 3 (a)-(d) correspond to $t=4$ and 5 hours, respectively. The pores interconnection is the most important structure characteristics of porous- $\mathrm{SiO}_{2}$ prepared in this work, by which the type of application is determined. Then, at the increasing of $(t)$ values, the verification of $\mathrm{SiO}_{2}$ became more obvious. This relation proves the porosity percent enhancement at increasing $(t)$. Figure $3(\mathrm{c})$ shows the particle size value $(0.59-1.16 \mu \mathrm{m})$ and the pore size that's nearly in the same range. But, at $t=5$ hours (Figure 3(b)), the $\mathrm{SiO}_{2}$ particle size range decrease to $(0.08-0.34 \mu \mathrm{m})$. So, SEM-images are in line with XRD data, as a result of complete conversion to the amorphous $-\mathrm{SiO}_{2}$. So, the product powder is suitable for using as heavy metal removal and dye removal as shown in last literatures [17].

The basic chemical reactions of $\mathrm{SiO}_{2}$ powder synthesis are presented in the following mechanism:

$$
\mathrm{Si}+2 \mathrm{KOH}+2 \mathrm{H}_{2} \mathrm{O} \rightarrow \mathrm{Si}(\mathrm{OH})_{4}+4 \mathrm{e}^{-}+2 \mathrm{~K}^{+}+\mathrm{H}_{2} \quad[18]
$$

At high $\mathrm{pH}$ range (alkaline medium) [1]:

$$
\begin{gathered}
\mathrm{Si}(\mathrm{OH})_{4}+\mathrm{OH}^{-} \rightarrow \mathrm{Si}(\mathrm{OH})_{3} \mathrm{O}^{-}+\mathrm{H}_{2} \mathrm{O} \\
\mathrm{Si}(\mathrm{OH})_{3} \mathrm{O}^{-}+\mathrm{Si}(\mathrm{OH})_{3} \mathrm{O}^{-} \rightarrow \mathrm{Si}(\mathrm{OH})_{3}-\mathrm{O}-\mathrm{Si}(\mathrm{OH})_{2} \mathrm{O}^{-}+\mathrm{OH}^{-}
\end{gathered}
$$

The $\mathrm{SiO}_{2}$ morphology [nano-porous-sphere and nano-porous-cubic] is visualized by TEM-images. Figure 4(a) and Figure 4(c) show the nano-porous-sphere $\mathrm{SiO}_{2}(90 \mathrm{~nm})$, with different geometric projections, that's synthesized at the

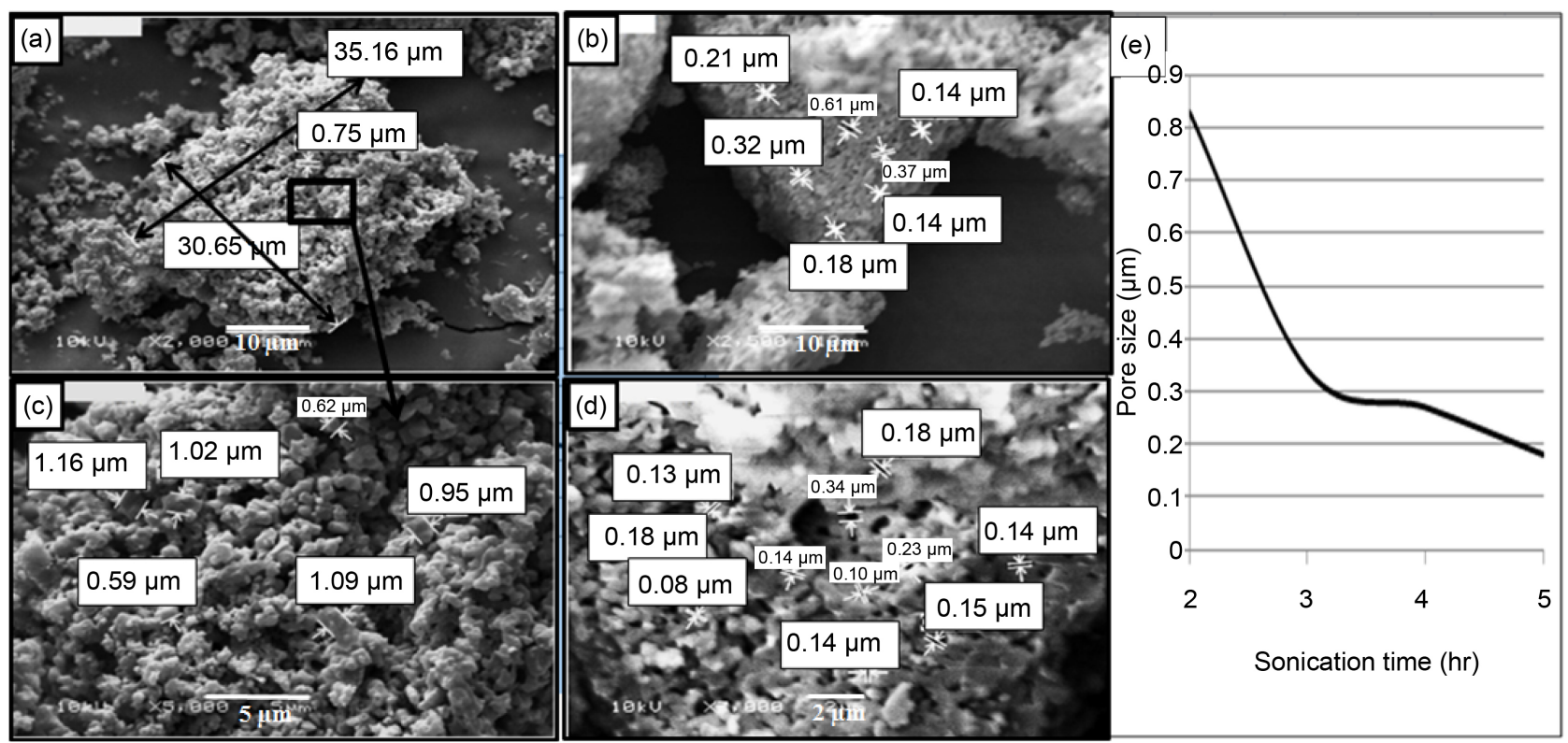

Figure 3. SEM images of porous- $\mathrm{SiO}_{2}$ obtained with (a) and (c) $6 \mathrm{wt} \% \mathrm{KOH}$ and $t=4 \mathrm{hr}$, (b) and (d) $6 \mathrm{wt} \% \mathrm{KOH}$ and $t=5 \mathrm{hr}$. (e) The relation between $t(\mathrm{hr})$ and the pore size $(\mu \mathrm{m})$. 


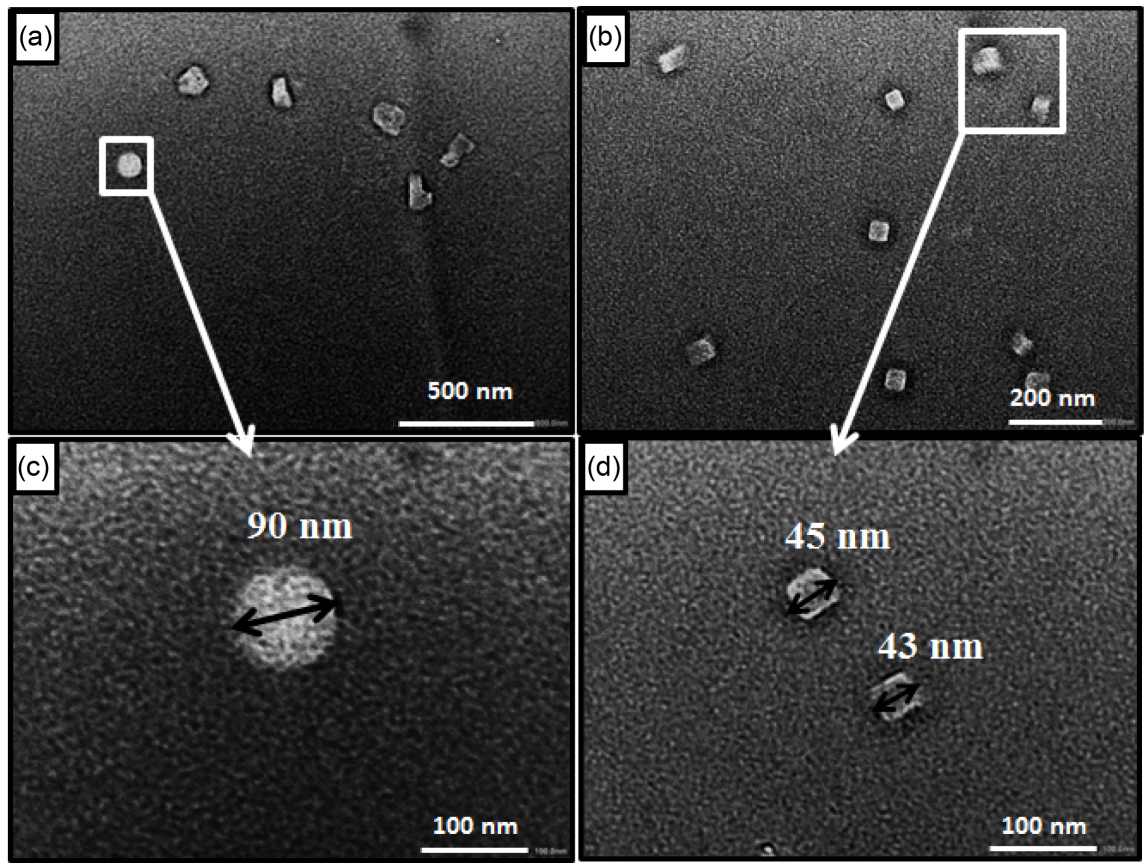

Figure 4. TEM-micrographs of $\mathrm{SiO}_{2}$-nanoparticles obtained with (a) and (c) $4.5 \mathrm{wt} \%$ $\mathrm{KOH}$ and $t=3 \mathrm{hr}$, (b) and (d) $4.5 \mathrm{wt} \% \mathrm{KOH}$ and $t=4 \mathrm{hr}$.

preparation conditions 4.5 weight $\% \mathrm{KOH}$ and $t=3$ hours. But, at $t=4$ hours, the nano-porous-cubic particles $(45 \mathrm{~nm})$ are appearing that agree the XRD-data in Figure 1(b). Then, it has high surface area that forms anion surfactants, which is used in many industrial applications [19]. Also, the crystalline- $\mathrm{SiO}_{2}$ [1] is recorded in Figure 4(b) and Figure 4(d). Then, the critical preparation conditions of porous-crystalline and amorphous- $\mathrm{SiO}_{2}$ are 6 weight $\% \mathrm{KOH}$ at $(t=4$ and 5 hours), as shown in Figure 1(c), Figures 3(a)-(d). Either in Figure 1(b) and Figures 4(a)-(d), at the different preparation conditions [4.5 weight \% $\mathrm{KOH}$ at $t=3$ and 4 hours], the nano-sphere and nano-cubic-SiO $\mathrm{S}_{2}$ shapes, respectively, are described.

Thus, it's found that the sonication time is controlled in the form and size of powder produced. Due to the ultra-sonication process is a growth inhibition technique especially in presence of alkali chemical etching process. So, the enhancement volume process is intermittently synchronized with the base etching process, causing the final shape of the product to change.

\section{Conclusion}

The pore size of the interconnected porous- $\mathrm{SiO}_{2}$ network in the micron range is successfully formed using commercial Si-powder as a cheap source of $\mathrm{SiO}_{2}$ (different morphological shapes). The particle size of the crystalline-porous- $\mathrm{SiO}_{2}$ powder is in range $(0.59-1.16 \mu \mathrm{m})$, but in case of amorphous one is in range $(0.08-0.34 \mu \mathrm{m})$. The successful production of $\mathrm{SiO}_{2}$ powder is through a combination ACE and ultra-sonication technique and subsequent drying at room temperature. It provided optimal conditions for the generation of micro-porous-crystalline 
and amorphous- $\mathrm{SiO}_{2}$ network. So, it's a novel method for controlling the synthesis of several $\mathrm{SiO}_{2}$-nano-shapes spherical $(90 \mathrm{~nm})$ and cubic $\left.(45 \mathrm{~nm})\right\}$ production.

\section{Conflicts of Interest}

The authors declare no conflicts of interest regarding the publication of this paper.

\section{References}

[1] Ui, S., Choi, I. and Choi, S. (2014) Synthesis of High Surface Area Mesoporous Silica Powder Using Anionic Surfactant. ISRN Material Science, 1, 834629-834635. https://doi.org/10.1155/2014/834629

[2] Smitha, S., Shajesh, P., Mukundan, P., Nair, T. and Warrier, K. (2007) Synthesis of Biocompatible Hydrophobic Silica-Gelatin Nano-Hybrid by Sol-Gel Process. Journal Colloids and Surfaces B: Biointerfaces, 55, 38-43. https://doi.org/10.1016/j.colsurfb.2006.11.008

[3] Joseph, R., Dorothy, R., Joany, R. and Pandiarajan, M. (2012) Corrosion Resistance of Nanoparticle Incorporated Nanocoatings. European Chemical Bulletin, 2, 965-970.

[4] Krasucka, P., Stefaniak, W., Kierys, A. and Goworek, J. (2015) One-Pot Synthesis of Two Different Highly Porous Silica Materials. Microporous and Mesoporous Materials, 221, 14-22. https://doi.org/10.1016/j.micromeso.2015.09.023

[5] Zeleáková, A., Zeleák, V., Matko, I., Streková, M., Hrubovák, M. and Ková, J. (2014)

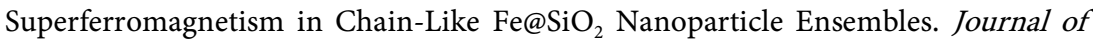
Applied Physics, 116, 033907-033914. https://doi.org/10.1063/1.4890354

[6] Xu, H., Liu, J., Du, H., Guo, A. and Hou, Z. (2012) Preparation of Porous Silica Ceramics with Relatively High Strength by a TBA-Based Gel-Casting Method. Chemical Engineering Journal, 183, 504-509. https://doi.org/10.1016/j.cej.2011.12.049

[7] Lv, H., Meng, F., Zhang, M., Geng, Z. and Sun, Y. (2015) Effect of the Drying Process on the Preparation of Porous Silica Microspheres. Chemica Engineering Science, 135, 285-293. https://doi.org/10.1016/j.ces.2015.03.050

[8] Azlina, H.N., Hasnidawani, J.N., Norita, H. and Surip, S.N. (2016) Synthesis of $\mathrm{SiO}_{2}$ Nanostructures Using Sol-Gel Method. Acta Physica Poloncia A, 129, 842-844. https://doi.org/10.12693/APhysPolA.129.842

[9] Bandyopadhyaya, R., Nativ-Roth, E., Yerushalmi-Rozen, R. and Regev, O. (2003) Transferable Thin Films of Mesoporous Silica. Chemistry of Materials, 15, 3619-3624. https://doi.org/10.1021/cm0310770

[10] Russo, L., Colangelo, F., Cioffi, R., Rea, I. and Stefano, L.D. (2011) A Mechanochemical Approach to Porous Silicon Nanoparticles Fabrication. Materials, 4, 1023-1033. https://doi.org/10.3390/ma4061023

[11] Nabil, M. and Motaweh, H.A. (2016) Enhanced Thermal Stability of Promising Nano-Porous Silicon Powder. Advances in Nanoparticles, 5, 199-205. https://doi.org/10.4236/anp.2016.54021

[12] Nabil, M., Mahmoud, K.R., El-Shaer, A.E. and Nayber, H.A. (2018) Preparation of Crystalline Silica (Quartz, Cristobalite, and Tridymite) and Amorphous Silica Powder (One Step). Journal of Physics and Chemistry of Solids, 121, 22-26. https://doi.org/10.1016/j.jpcs.2018.05.001 
[13] Jafarzadeh, M., Adnan, R. and Mazlan, M.K.N. (2012) Thermal Stability and Optical Property of Ormocers (Organically Modified Ceramics) Nanoparticles Produced from Copolymerization Between Amino-Silanes and Tetraethoxysilane. Journal of Non-Crystalline Solids, 358, 2981-2987. https://doi.org/10.1016/j.jnoncrysol.2012.07.028

[14] Phuong, H.T., Hong, N.K.D. and Ngo, D.T. (2016) Study on Surface Modification of Nanosilica Aerogel for Oil Adsorption on Surface Oil Polluted Water. Vietnam Journal of Chemistry, 54, 426-430.

[15] Musić, S., Filipović-Vinceković, N. and Sekovanić, L. (2011) Precipitation of Amorphous $\mathrm{SiO}_{2}$ Particles and Their Properties. Brazilian Journal of Chemical Engineering, 28, 89-94. https://doi.org/10.1590/S0104-66322011000100011

[16] Mourhly, A., Khachani, M., El Hamidi, A., Kacimi, M., Halim, M. and Arsalane, S. (2015) The Synthesis and Characterization of Low-Cost Mesoporous Silica $\mathrm{SiO}_{2}$ from Local Pumice Rock. Nanomaterial and Nanotechnology, 5, 35-41.

https://doi.org/10.5772/62033

[17] Ahmad, I., Siddiqui, W. and Ahmad, T. (2017) Synthesis, Characterization of Silica Nanoparticles and Adsorption Removal of $\mathrm{Cu}^{2+}$ Ions in Aqueous Solution. International Journal of Emerging Technology and Advanced Engineering, 7, 439-445.

[18] Kashyout, A.E.H. and Nabil, M. (2018) Production of High Throughput Nano-Porous Silicon (NPS) Powder with Different Architectures. Materials Chemistry and Physics, 216, 454-459. https://doi.org/10.1016/j.matchemphys.2018.05.048

[19] Sang-wook, U., In-seok, C. and Sung-churl, C. (2014) Synthesis of High Surface Area Mesoporous Silica Powder Using Anionic Surfactant. ISRN Materials Science, $1,1-6$. 